\title{
The Eco-transformation of Nanchang National Hi-tech Industrial Development Zone under the new economic norm
}

\author{
Xiaoting Liu ${ }^{1,}$, Jinwen Zhong ${ }^{2, b}$ \\ ${ }^{1}$ School of Business, Jiangxi Normal University, Nanchang, China \\ ${ }^{2}$ School of Business, Jiangxi Normal University, Nanchang, China \\ a642134084@qq.com, bjw650583@126.com
}

\begin{abstract}
Keywords: Economic new normal, Ecological, Recycling economy, Low-carbon.
Abstract. The deep transformation of green development of economic is the trend of the new normal of China's economy. Nanchang National Hi-tech Industrial Development Zone has developed rapidly, but there are still many problems in the process of its development, which need to ensure the sustainable development of the park through the ecological transformation. In this paper, using scientific methods to find the crux of the park development under the new norm, and doing ecological transformation from four aspects, improve the mode of circular economy, establish environmental protection incentive mechanism, green investment, low-carbon construction. It provides theoretical guidance for the ecological development and industrial distribution of Nanchang hi tech zone.
\end{abstract}

\section{Introduction}

Under the new economic norm, China must develop the green economy and low-carbon economy and circular economy, must put the construction of ecological civilization in a prominent position to make good use of resources of environment, maintain the sustainable ability of nature for human beings, and leave more space for development of descendants. Industrial park as a business cluster, the backbone of the economic development of major cities, new engin of stimulating regional economic growth, its sustainable development is essential. So this paper takes the Nanchang National Hi-tech Industrial Development Zone(NC Hi-tech Zone) as an example, carries on the investigation and study, discusses the existing problems in the process of developing. Aiming at these problems, puts forward the ways of Eco-transformation.

\section{Literature review on Eco-Industrial Park}

Frosh etc. first proposed the concept of industrial ecology in 1989, and considered that it should make comprehensive research on different industrial processes, the waste circulate to achieve the purpose of recycling. "Eco-industrial park is an industrial system that holds natural and economic resources and provides opportunities for waste utilization and sales profit," Cote and Hall said. Lowe, Moran and Holines etc. emphasied the cooperation mechanism of Eco-industrial Park, it is a community of manufacturing and service industry, seeking collective benefits through cooperation in environmental and resource management, and the benefit is greater than the sum of the interests of each company to achieve when optimizing their respective interests.

China's State Environmental Protection Administration defined the Eco-industrial park as a new type of industrial park designed according to the requirements of clean production, circular economy and industrial ecology. China has been actively developing economic research related to the construction and development of Eco-industrial parks in recent years, many scholars believed that the Eco-industrial park is the combination of the circular economy and systematic thinking of industrial ecology. Ning Duan believed that the proper design of the park logistics and energy flow, the simulation of natural ecosystems, the formation of symbiotic network of enterprises, and graded use of energy can achieve ecological industry; Jiaping Xie put forward the goal of upgrading the industrial park, promoting measures and related policy recommendations from the circulation level of industrial ecology; Yonghui Cao considerded the advantages and disadvantages of four symbiotic networks should be taken into 
construction of eco industrial parks. Beibei Cheng etc. constructed the evaluation index system of output system, resource system, life index, and policy index about eco industrial park. And aout NC Hi-tech Zone, Qiong Liu, Min Xie, Haiwu Wei etc. gived the relevant recommendations from the circular economy, clean production, construction of the industrial chain.

\section{Research method}

Through the field survey in the NC Hi-tech Zone, and design, release, recover and summary the questionnaire; then analyze and compare the data to draw a conclusion to get the solution. The data collection methods of this study mainly include: semi structured interview, field observation, secondary data collection and questionnaire survey, a variety of data sources ensure the reliability of the study. In data analysis, Firstly, the data is encoded, the first hand data from interviews and field observations and questionnairesis is encoded into classI, the second hand data from NC Hi-tech Zone website and the administrative committee and the enterprise is encoded into classII; Secondly, according to the domestic and foreign documents, express the concept of existing problems in NC Hi-tech Zone .

\section{The path of Eco-transformation of NC Hi-tech Zone}

According to the data of the research and the experience of Chinese and foreign Hi-tech Zone, the author believes that the Eco-transformation of NC Hi-tech Zone can be taken as follows.

\section{Improvement of development model of circular economy}

Only photovoltaic LED industry and bio-pharmaceutical industry have a complete industrial chain in NC Hi-tech Zone, other industries have not been able to play a very good industrial agglomeration effect, not really achieve resource sharing and waste exchange and the effects of industrial symbiosis. Therefore, the development of circular economy has to start from the construction of the industrial symbiosis system construction, public infrastructure, and social cycle.

To build and perfect the symbiotic system. The aviation industry and new materials industry should learn from the photovoltaic industry and bio pharmaceutical industry, leading enterprises promot small and medium enterprises to form upstream and downstream industry chains to achieve the circulation of waste water and waste heat and exhaust gas, further formation of industrial symbiosis network, through the industrial chain of vertical and horizontal extension, to achieve the waste of resources, energy minimization. Through the vertical and horizontal extension of the industrial chain, to achieve the minimize waste of resources and energy.

To construct public infrastructure. To construct sewage plant and refuse incinerator to deal with the waste produced by various enterprises, and the enterprises pay the fees according to the amount; to construct public heat energy generating device in use of heat energy released from sewage treatment and production process; to construct public natural gas transmission network. the construction of public facilities can use the resources and energy efficiency efficiently, reduce energy and waste of resources; can urge the enterprises to reduce the behavior of free waste disposal.

To start the social level cycle. Form the circulation of "natural resources-industry-renewable resources" in the whole society, enterprises can't stick to the small circle of self-sufficiency, should actively integrate into a wider range of economic cycle to adapt to development trend of the new economic norm.

\section{To establish environment protection compensation and promotion mechanism}

The NC Hi-tech Zone exits the serious pollution problems, such as wanton discharge of waste gas and waste water, noise, faulty goods etc., and government lax supervision, enterprises have no intention to clean production, So NC Hi-tech Zone has to establish environment protection compensation and promotion mechanism to completely change this situation. 
Firstly, government should develop a clear and strong enforcement of environmental protection laws and regulations. In order to avoid high fines of the environmental pollution, enterprises should take various measures such as green procurement, green production to reduce the environmental pollution produced in the production process; and incentive measures will be rewarded for enterprises which put investment funds in the green production, to give its subsidies and derate part of the sewage tax. Secondly, the NC Hi-tech Zone should develop and implement clear green indicators and rules to guide and promote enterprises' green production.

Thirdly, the government needs to guide consumers green consumption. To regulate the proportion of producers' income, make up for the benefits of green manufacturing enterprises and narrow the income gap between green and non green manufacturing enterprises, improve the yield of green products, stimulate consumer demand.

\section{Green investment and backward production capacity}

Geographical position and economic development constraints of NC Hi-tech Zone lead less investment, the NC Hi-tech Zone undertake the eastern coastal pollution or high energy consumption in the low-end industrial transfer, not considering the enterprises in the park layout, or the introduction of some existing businesses and parks within the reach of coupling related enterprises, leading enterprises in the park "not set", industry correlation is not strong, it is not conducive to ecological construction. Firstly, the NC Hi-tech Zone set up a high threshold of environmental protection, set up a variety of environmental indicators to assess the investment enterprises, such as domestic sewage treatment rate, comprehensive utilization rate of industrial solid waste, $\mathrm{SO}_{2}$ emission coefficient of elasticity, $\mathrm{CO}_{2}$ emission coefficient of elasticity and industrial water reuse rate to pick out the high economic efficiency and low carbon type of enterprises, and refuse unqualified enterprises.

Secondly, the NC Hi-tech Zone should drive out enterprises with serious pollution and low comprehensive efficiency and backward production capacity, then attract more green production enterprises to join in, and build a new eco-industrial park.

Finally, the park should be strengthened in the software outsourcing industry and financial industry and technology industry investment promotion work.

\section{Low carbonization construction}

There are many problems in the construction of low carbon construction, such as immature low carbon planning, no optimal low carbon program, low coverage of renewable energy utilization, no professional environmental protection mechanism. The low carbonization constructionof the park needs many aspects of coordination.

Firstly, NC Hi-tech Zone should optimize the energy structure, according to the excellent environmental resources, develop and utilize new energy and increase the use of renewable energy, reduce carbon emissions, encourage enterprises to innovate low-carbon energy, improve energy efficiency.

Secondly, NC Hi-tech Zone need plan low carbon building system, construct low carbon building standards, promote the use of natural light sources and wind and solar and other renewable energy.

Thirdly, NC Hi-tech Zone can build a low carbon transportation system. The park should establish a travel system with public transport as the main and other means of transportation, increase investment in low-carbon and zero carbon transport, such as electric vehicles and public bicycles, encourage scientific and technological enterprises to innovate the development of low carbon transport vehicles, and promote the application of other new energy vehicles.

Finally, NC Hi-tech Zone establish a non-profit organization which is responsible for the development of various fields of industrial and energy structure optimization, low-carbon building demonstration, low-carbon transportation system construction, low-carbon concept promotion and international cooperation mechanism innovation. 


\section{Conclusions}

The paper finds that the shackles existed in the park through the investigation and analysis of data and information, on the basis of deep understanding of the NC Hi-tech Zone, puts forward the ways to improve the eco-transformation from the aspects of improving the recycling economy, establishing the incentive mechanism of environmental protection, the construction of green investment and low carbonization. Under the new economic norm, the exploration of this paper has a good reference for the development of NC Hi-tech Zone, which is conducive to the sustainable development of the high tech Zone. But it is still limited, the new economic norm is still at an early stage, a variety of policies and regulations are not clear, there may be unknown areas in the ecological development of the park, will deepen this problem in the future research.

\section{Acknowledgements}

This work was financially supported by the National Natural Science Fund Project (71463028), Jiangxi Social Science Program (11YJ41), Jiangxi College Humanities and Social Science Project (JC1111), and Science and Technology Project of Educationt Department of Jiangxi Province (GJJ12200), and Jiangxi Soft Science Project(20121BBA10022).

\section{References}

[1] Junhua Li. The transformation path and optimization direction of China's industrial development mode under the new normal state[J]. Modern economic research, 2015 (2): 10-15.(In Chinese)

[2] Beibei Cheng, Peng Wang, Daiqing Zhao. Low carbon industrial park planning method and evaluation index system[J]. Ecological economy, 2013 (5): 126-135.(In Chinese)

[3] Mathews J A,Tan H. Progress towards a Circular Economy in China:The Drivers(and Inhibitors) of Eco-industrial Initiative[J].Journal of Industiral Ecology,2011,15(3):435-457.

[4] Zhang L, Yuan Z W,Bi J,et al.Eco-industrial Parks:National Pilot Practices in China[J].Journal of Cleaner Production,2010,18(5):540-509.

[5] Xiaoqing $\mathrm{Wu}$. Take the initiative to adapt to the new economic norm to vigorously promote the new development of the environmental protection industry [J]. Environmental protection, 2015 (5):12-15.(In Chinese) 